\title{
High-Temperature Oxidation Mechanism in 2.5\% Tin-Zirconium Alloy*
}

\author{
By Tatsuo Maekawa** and Bunpei Ishii**
}

\begin{abstract}
The breakaway oxidation, mainly at $850^{\circ} \mathrm{C}$, of $2.5 \%$ tin-zirconium alloy in oxygen has been investigated by thermogravimetric measurement, electron microscopic observation, electron-probe microanalysis and X-ray diffraction analysis. In the post-breakaway stage, the oxidation kinetics was remarkably affected by the pressure of oxygen, and severe cracking of the oxide film was observed. The electron-probe microanalysis and X-ray diffraction analyses indicated that the tin in the alloy was precipitated as an intermetallic compound of $\mathrm{ZrSn}$ at the oxide/metal interface, and suggested that the oxide film has a multilayer structre consisting of $\mathrm{ZrO}_{2}$ and $(\mathrm{ZrSn}) \mathrm{O}_{2}$ layers. The mechanism of the pronounced breakaway phenomenon of tin-zirconium alloy was discussed on the basis of the behavior of tin in the alloy, and it was concluded that stress between the layers of $\mathrm{ZrO}_{2}$ and $(\mathrm{ZrSn}) \mathrm{O}_{2}$ induced the cracking of the oxide film and permitted the increased oxidation.
\end{abstract}

(Received February 28, 1966)

\section{Introduction}

The oxidation or corrosion processes of zirconium and its alloys have been studied by many workers. The majority of the investigators have found that initially

* This paper was published in Japanese in the Journal of the Japan Institute of Metals, 30 (1966), 270.

** Engineering and Research Laboratory, Mitsubishi Atomic Power Industries, Inc., Ohmiya, Saitama, Japan. zirconium oxidizes according to a cubic or parabolic rate law and then undergoes a transition from cubic (or parabolic) to linear kinetics. The transition of the oxidation rate, the so-called "breakaway phenomenon", is influenced by the purity of the specimen, corrosion environment, and temperature. The oxidation of pure zirconium in pure oxygen has been studied by many workers $^{(1) \sim(9)}$, and it has been reported that pure zirconium does not exhibit any transition in oxidation 
rate at high temperature up to several hundred hours of oxidation. In contrast to pure zirconium, the $\mathrm{Zr}-\mathrm{Sn}$ alloy was found to undergo a transition in rate in a very short time. Mallett et al. (10) have studied the oxidation of 1.5 and $2.5 \%, \mathrm{Sn}-\mathrm{Zr}$ alloys in oxygen at high temperature, and Porte et al. ${ }^{(2)}$ have studied that of $0.96,1.68$ and $3.6 \% \mathrm{Sn}-\mathrm{Zr}$ alloys. Glubransen et al. ${ }^{(11)}$ and Westerman $^{(5)}$ studied the oxidation of Zircaloy-2 and -3a, Zircaloy- 2 in oxygen, respectively. According to these works, the time to transition of the $\mathrm{Zr}$-Sn alloys is in the range from several tens to several hundreds of minutes, being a function of temeperature and tin content.

Although a number of mechanisms of the breakaway phenomenon of zirconium have been proposed by many workers, the mechanism of the accelerated breakaway phenomenon in $\mathrm{Zr}$-Sn alloys has not been satisfactorily explained yet. The purpose of the present study was to investigate the behavior of tin in the oxidation process of the $\mathrm{Zr}-\mathrm{Sn}$ alloy, and to explain the role of tin in the breakaway phenomenon.

\section{Experimental Procedure}

A $\mathrm{Zn}-\mathrm{Sn}$ alloy of $2.5 \mathrm{wt} \% \mathrm{Sn}$ was used for this study. The alloy was made by double arc-melting of a mixture of the reactor-grade zirconium sponge and tin granules in argon atmosphere. The analysis of the sponge is shown in Table 1. The alloy was forged and cold-rolled

Table 1 Analysis of zirconium sponge used.

\begin{tabular}{c|c}
\hline Impurities & Contents (wt \%) \\
\hline $\mathrm{Al}$ & 0.0045 \\
$\mathrm{~B}$ & 0.00004 \\
$\mathrm{C}$ & 0.01 \\
$\mathrm{Ca}$ & 0.002 \\
$\mathrm{Cl}$ & 0.0027 \\
$\mathrm{Cr}$ & 0.0088 \\
$\mathrm{Co}$ & 0.0005 \\
$\mathrm{Cu}$ & 0.0001 \\
$\mathrm{Fe}$ & 0.029 \\
$\mathrm{Hf}$ & 0.0080 \\
$\mathrm{Mg}$ & 0.0027 \\
$\mathrm{Mn}$ & 0.0026 \\
$\mathrm{Ni}$ & 0.003 \\
$\mathrm{~N}$ & 0.0021 \\
$\mathrm{~Pb}$ & 0.001 \\
$\mathrm{Si}$ & 0.0015 \\
$\mathrm{Ti}$ & 0.003 \\
$\mathrm{~V}$ & 0.002 \\
\hline
\end{tabular}

to a $0.5 \mathrm{~mm}$ sheet, and annealed in vacuo at $750^{\circ} \mathrm{C}$ for 3 hours. The sheet was abraded with $0 / 4$ emery paper

(1) J. Belle and M. W. Mallett : J. Electrochem. Soc., 101 (1954), 339.

(2) H. A. Porte, J. G. Schnizlein, R. C. Vogel and D. F. Fisch: ibid, 107 (1960), 506.

(3) K. Östhagen and P. Kofstad : ibid, 109 (1962), 204.

(4) K. A. Sense : ibid, 109 (1962), 377.

(5) R. E. Westerman : ibid, 111 (1964), 140.

(6) C, R. Wallwork, W. W. Smeltzer and C. J. Rosa : Acta Met., 12 (1964), 409.

(7) R. J. Hussey and W. W. Smeltzer : J. Electrochem. Soc., 111 (1964), 564 .

(8) R. J. Hussey and W. W. Smeltzer : ibid, 111 (1964), 1121.

(9) C. R. Wallwork, C. J. Rosa and W. W. Smeltzer : Corrosion Sciencc, 5 (1965), 113.

(10) M. W. Mallett and W. M. Albrecht : J. Electrochem. Soc., 102 (1955), 407.

(11) E. A.Gulbransen and K. F. Andrew : Trans. AIME, 212 (1958), 281. and pickled in $5 \% \mathrm{HF}-45 \% \mathrm{HNO}_{3}$ aqueous solution for 3 minutes. The oxygen used in these experiments was taken directly from the commercial oxygen tank $\left\langle\mathrm{O}_{2}\right\rangle$ $99.8 \%$, dew point $<-50^{\circ} \mathrm{C}$ ) without further purification.

The oxidation rate of the alloy was measured by a thermogravimetric balance in the oxygen atmosphere. Until the breakaway time the alloy was oxidized under atmospheric pressure, and in the post-breakaway stage the pressure of oxygen was changed successively to 1 atm., $100 \mathrm{mmHg}, 15 \mathrm{mmHg}, 200 \mathrm{mmHg}$ and $1 \mathrm{~atm}$., to study the effect of pressure on the oxidation rate.

Electron microscopic observations on surfaces and cross-sections of the oxidized specimens were performed using a JEM-5Y electron microscope. Replica films for electron microscopic observations were prepared by the two-stage method and were shadowed in vacuo by metallic chromium at an angle of about 45 degrees. In order to measure the distribution of tin in the oxidized specimens, an electron-probe microanalysis of tin in one of the oxidized specimens was carried out. The specimens for microscopic observation and microanalysis of the cross-section were put in polyester resin and abraded with $5 / 0$ emery paper. For the electron microscopic observations the cross-section was etched in 5\% $\mathrm{HF}-45$ $\% \mathrm{HNO}_{3}$ aqueous solution. However, for the electronprobe microanalysis it was not etched, to avoid any change of the composition, but a thin carbon film was deposited on the surface by an evaporation method to give electric conductivity to the oxide film. An electronprobe microanalyzer of type JAX-3 was used for this study. The condition of the analysis was as follows: accelerating voltage, $25 \mathrm{kV}$; beam spot size, $0.5 \sim 0.8 \mu$; analyzing crystals, Quartz $\left(\mathrm{SnK}_{\alpha}\right)$ and Mica $\left(\mathrm{ZrK}_{\alpha}\right)$; sweeping speed, $10 \mu / \mathrm{min}$.; and time constant, 2 sec.

Furthermore, since it was possible to peel off the oxide film on the heavily oxidized specimens from near the metal/oxide interface, electron microscopic observations, microanalysis of tin content and X-ray diffraction analysis were carried out on the peeled surface to investigate the structure of the metal/oxide interface. The $\mathrm{X}$-ray diffraction analysis was made by using an X-ray diffractometer of $\mathrm{CuK} \alpha$ radiation.

\section{Results}

\section{Oxidation rate}

Fig. 1 shows the oxidation rate of pure zirconium and the $2.5 \% \mathrm{Sn}-\mathrm{Zr}$ alloy at $850^{\circ} \mathrm{C}$. In the oxidation process of pure zirconium, the breakaway phenomenon is observed only in air, and is not observed in oxygen atmosphere. In contrast to the pure zirconium, in the oxidation process of the $2.5 \% \mathrm{Zr}$-Sn alloy a severe breakaway phenomenon is observed in oxygen atmosphere within the initial 10 minutes and the oxidation rate increases abruptly. The results agree with those in the previous literature(2)(10)(12).

Fig. 2 shows the oxidation rates of the $2.5 \% \mathrm{Sn}-\mathrm{Zr}$ alloy at several different pressures of oxygen in the postbreakaway stage, indicating that the oxidation rates are affected rapidly by oxygen pressure. From Fig. 2 the

(12) T. Maekawa and B.Ishii : Trans. JIM, 3 (1962), 203. 


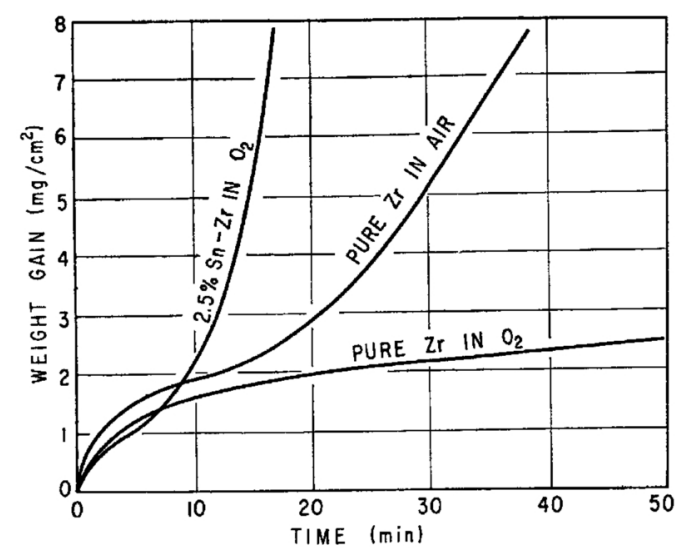

Fig. 1 Oxidation of pure zirconium and $2.5 \% \mathrm{Sn}-\mathrm{Zr}$ alloy at $850^{\circ} \mathrm{C}$ under atmospheric pressure. oxidation rate constants at given oxygen pressures are calculated, assuming a linear oxidation rate law, and the relation between the logarithm of the rate constant and that of pressure are shown in Fig. 3. This figure indicates that the relation between the rate constant and pressure is expressed by the following equation :

$$
k=k_{\iota} P^{n}
$$

where $k$ : oxidation rate constant at given pressure $k_{o}$ : oxidation rate constant at standard pressure $P$ : pressure of oxygen $n:$ constant

The value $n$ is a constant related to the pressure dependence of the oxidation rate which indicates the degree of the protective property of the oxide film. Fig. 3 indicates that $n$ is small below $600^{\circ} \mathrm{C}$; however, it increases with increasing temperature, and it becomes

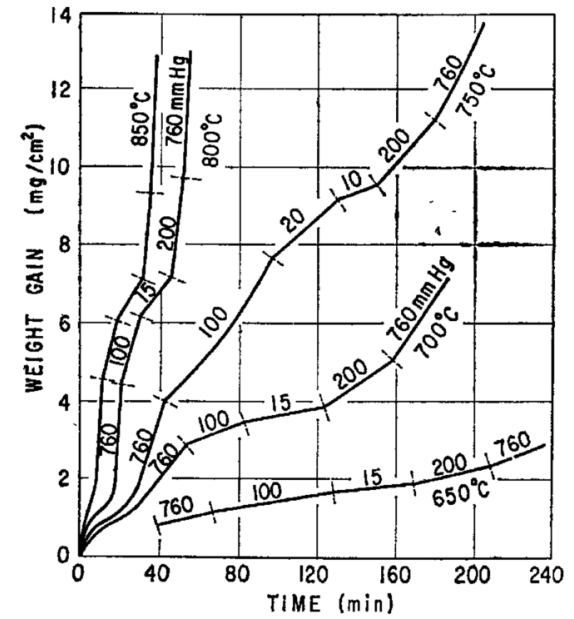

Fig. 2 Effect of pressure on post-breakaway oxidation of $2.5 \% \mathrm{Sn}-\mathrm{Zr}$ alloy in oxygen.

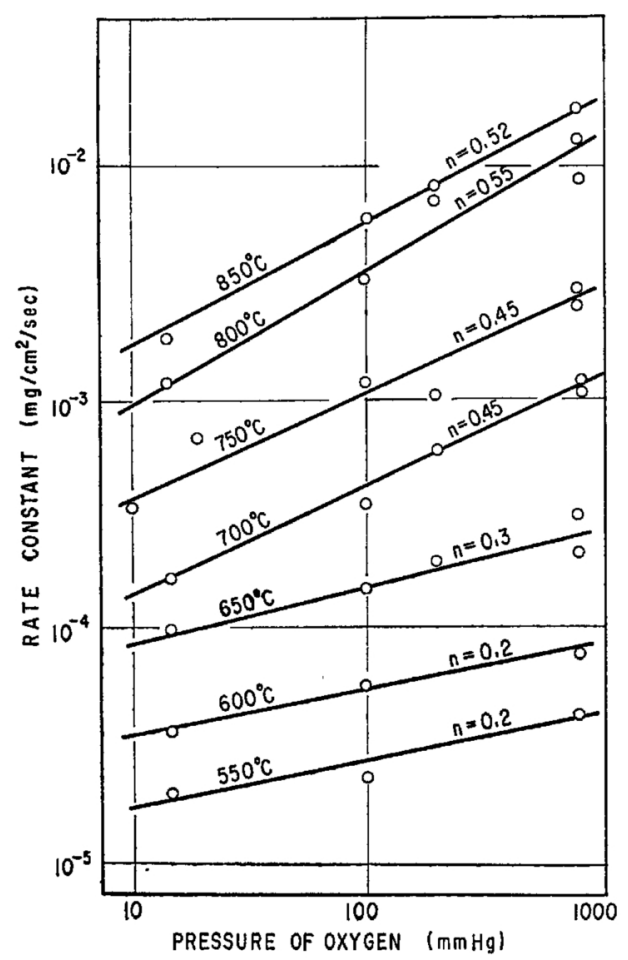

Fig. 3 Pressure dependence of rate constants for postbreakaway oxidgtion of $2.5 \% \mathrm{Sn}-\mathrm{Zr}$ alloy.

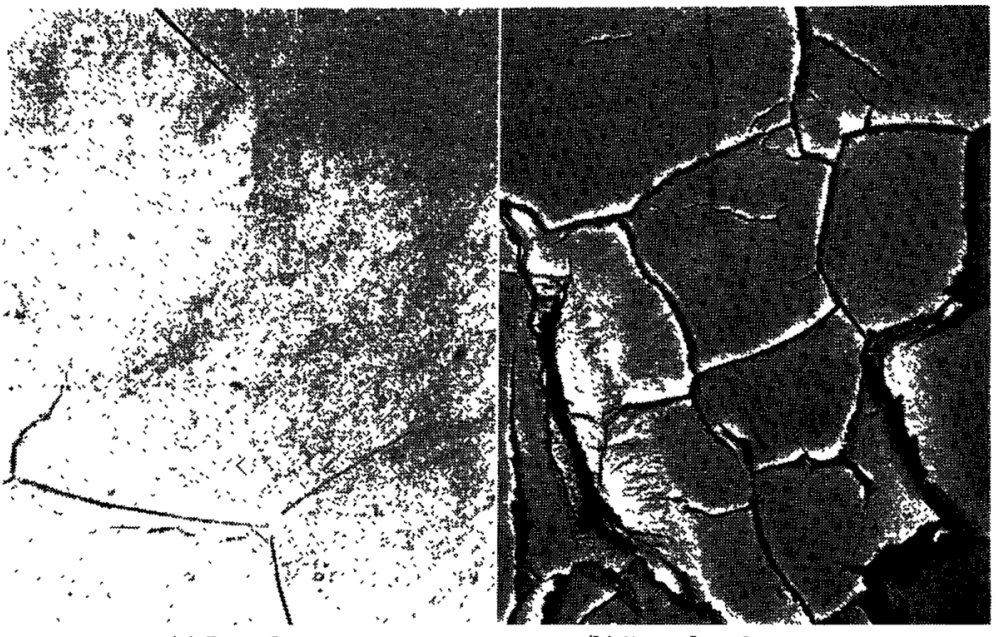

(a) Initial stage (10 min)

(b) Post-breakaway stage

(30 min)

Photo. 1 Electron micrographe of oxidized surfaces of $2.5 \% \mathrm{Sn}-\mathrm{Zr}$ in oxygen at $850^{\circ} \mathrm{C} . \quad(\times 3000)$

$0.45 \sim 0.55$ above $700^{\circ} \mathrm{C}$. This means that the oxidation rate above $700^{\circ} \mathrm{C}$ increases approximately in proportion to the square root of oxygen pressure.

\section{Electron microscopic observations}

Photo. 1 shows two typical surfaces of the $2.5 \% \mathrm{Sn}$ $\mathrm{Zr}$ alloy oxidized at $850^{\circ} \mathrm{C}$ in oxygen. Photograph (a) shows a surface after 10 minutes of oxidation, a typical surface in the initial stage of oxidation. In this stage, the alloy is covered with a black adherent oxide film, and a parabolic oxidation rate law can be applied. In this photograph only small cracks along the grain boundary are observed. Photograph (b) indicates the surface after 30 minutes of oxidation, a typical surface in the post-breakaway stage. The surface looks white to the naked eye and the electron micrograph shows heavier cracking within the grains.

Photo. 2 shows two electron micrographs of crosssections of the two oxidized specimens in Photo.1. Photograph(a) shows a cross-section of the oxidized specimen in the initial stage, which indicates no cracking in the oxide film or at the metal/oxide interface. Photograph (b) is a cross-section in the post-breakaway stage. In this photograph large cracks can be observed at the metal/ oxide interface and in the oxide layer along the interface. 
The oxide film on the specimen oxidized in the postbreakaway stage can be peeled off easily from near the metal/oxide interface. Photo. 3 shows two electron micrographs of the peeled surface. Photograph (a) shows the peeled surface of the metal side, which teristic X-rays from the alloy and the pure metal. Since the X-ray intensities have not been corrected for various factors, Fig. 4 does not always indicate the absolute concentrations of the elements; however, it is possible to estimate the variation of the tin contents in the alloy and

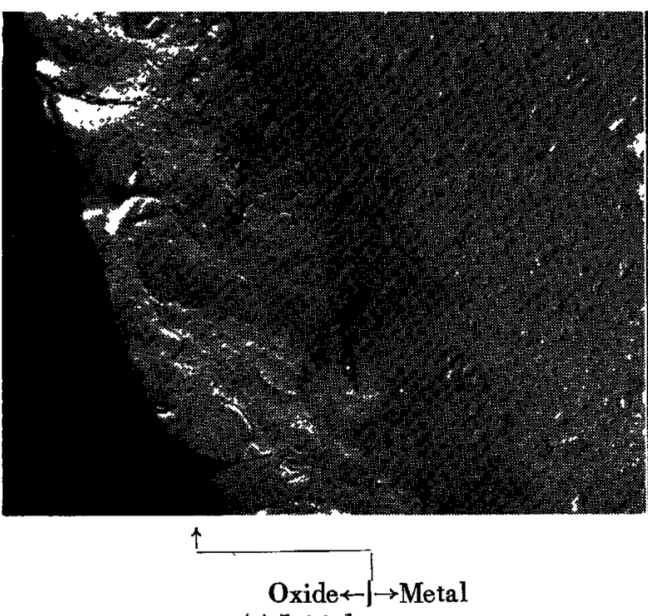

(a) Initial stage (10 $\mathrm{min})$

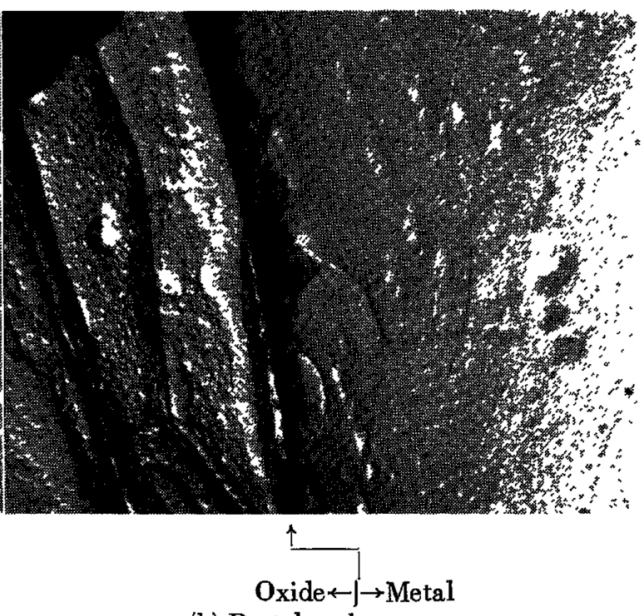

(b) Post-breakaway stage (30 min)

Photo. 2 Electron micrographs of cross-sections of $2.5 \% \mathrm{Sn}-\mathrm{Zr}$ oxidized in oxygen at $850^{\circ} \mathrm{C}$. (Etched in 5\% $\mathrm{HF}-45 \% \mathrm{HNO}_{3} \mathrm{aq}$.) $(\times 1500)$

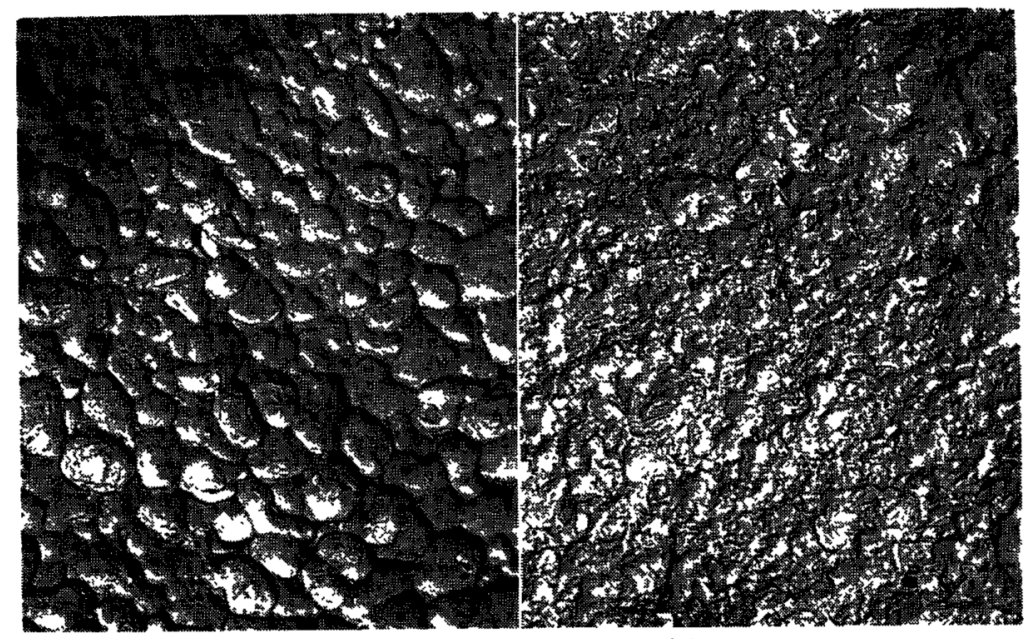

(a) Metal side

(b) Oxide side

Photo. 3 Electron micrographs of surface peeled from oxide/metal interface of $2.5 \% \mathrm{Sn}-\mathrm{Zr}$ oxidized in oxygen at $850^{\circ} \mathrm{C}$ for $30 \mathrm{~min} . \quad(\times 3000)$

indicates deposits of particles two or three microns in diameter. Photograph (b) shows that of the oxide side, which indicates the unevenness corresponding to the structure of the metal side surface.

Photo. 4 shows an electron micrograph of the crosssection of the oxide film of the post-breakaway stage. The cross-section of the oxide film is etched in $1 \% \mathrm{HF}$ $99 \% \mathrm{HNO}_{3}$. This photograph shows that the film consists of many layers which are separated by continuously deposited small particles.

\section{Analysis by electron-probe microanalyzer}

In order to measure the distribution of tin and zirconium in the alloy and oxide film, line analyses of tin and zirconium were carried out across the metal/oxide interface of a typical cross-section of the breakaway specimen. Fig. 4 shwos a typical distribution of tin and zirconium in the cross-section corresponding to Photo.2,(b). The vertical axis in Fig. 4 in dicates the intensity ratio of charac-

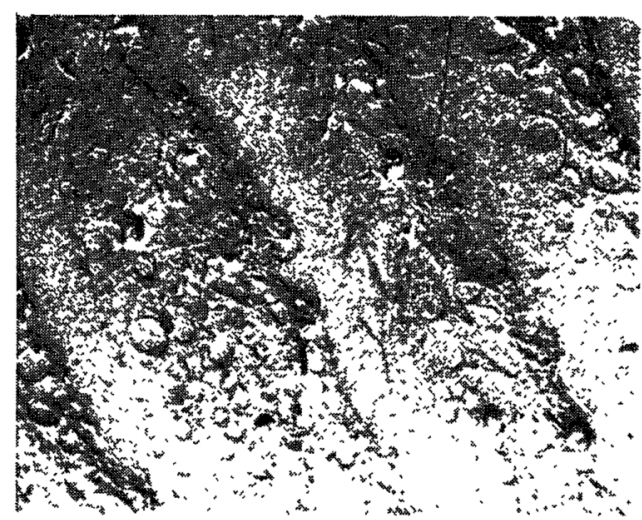

Photo. 4 Electron micrograph of cross-section of oxide of $2.5 \% \mathrm{Sn}-\mathrm{Zr}$ oxidized in oxygen at $850^{\circ} \mathrm{C}$ for 30 minutes. (Etched in $\left.1 \% \mathrm{HF}-99 \% \mathrm{HNO}_{3}\right)(\times 4500)$

the oxide film. The position of the metal/oxide interface is determined from the abrupt change in the ab- 
sorbed current intensity. Fig. 4 indicates that tin is enriched at the metal/oxide interface. Fig. 5 shows the line analysis of tin and zirconium on the peeled surface corresponding to the electron micrograph of Photo. 3 , (a) which indicates deposits of small particles. This

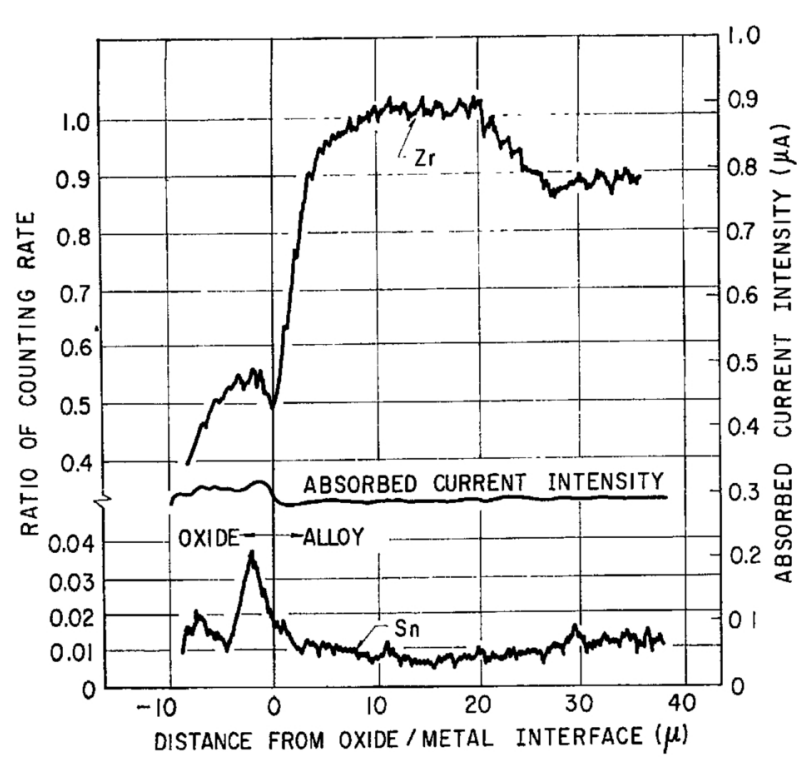

Fig. 4 Distribution of tin and zirconium through alloy and scale for $2.5 \% \mathrm{Sn}-\mathrm{Zr}$ oxidized in oxygen at $850^{\circ} \mathrm{C}$ for $30 \mathrm{~min}$.

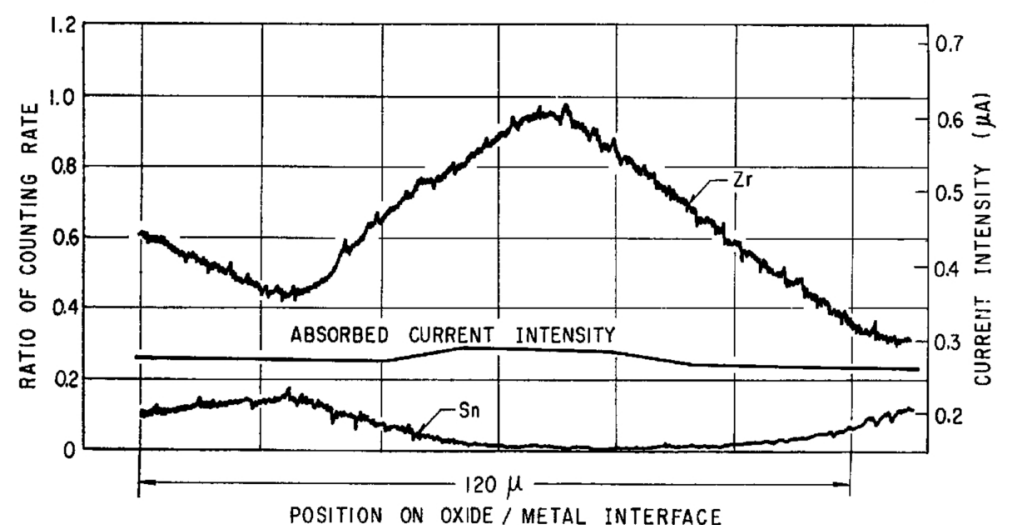

Fig. 5 Distribution of tin and zirconium on the metal side of oxide/metal interface of $2.5 \% \mathrm{Sn}-\mathrm{Zr}$ oxidized in oxygen at $850^{\circ} \mathrm{C}$ for $30 \mathrm{~min}$.

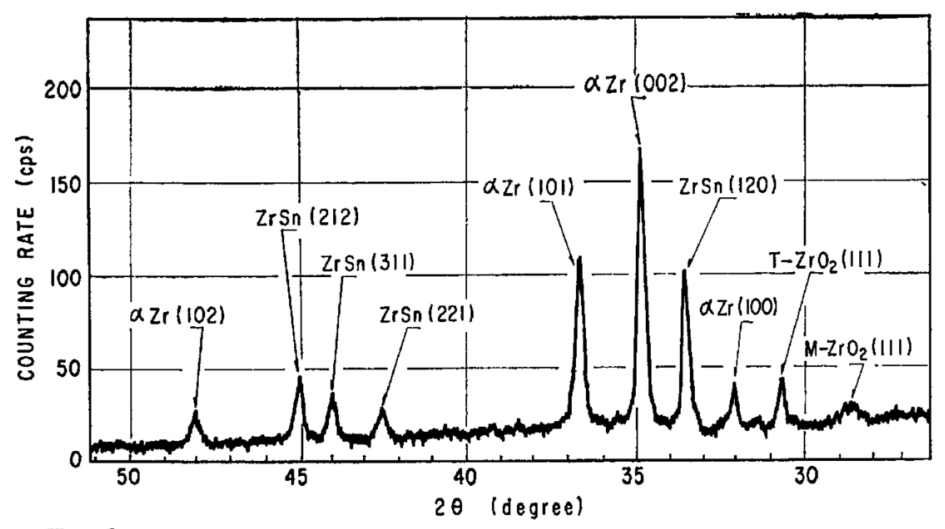

Fig. $6 \mathrm{X}$-ray diffraction of the metal side of the oxide/metal interface of $2.5 \% \mathrm{Sn}-\mathrm{Zr}$ oxidized in oxygen at $850^{\circ} \mathrm{C}$ for $30 \mathrm{~min}$ by $\mathrm{CuK}_{\alpha}$ radiation.

figure indicates that there is a highly concentrated area of tin on the peeled surface of the metal side.

In order to study the structure near the metal/oxide interface, X-ray diffraction of the peeled surface was carried out using an X-ray diffractometer of $\mathrm{CuK}_{\alpha}$ radiation. Fig. 6 shows a diffraction chart of the peeled surface of the metal side. In this figure are observed the diffraction lines of $\alpha \mathrm{Zr}$, tetragonal- $\mathrm{ZrO}_{2}$, monoclinic$\mathrm{ZrO}_{2}$ and $\mathrm{ZrSn}$, an intermetallic compound of zirconium and tin.

\section{Discussion and Conclusion}

As described above, it was found that $2.5 \% \mathrm{Sn}-\mathrm{Zr}$ alloy indicated a pronounced breakaway phenomenon, and the oxidation in the post-breakaway stage proceeded approximately in proportion to the square root of oxygen pressure at high temperature. This suggests that the oxide film on the breakaway specimen does not afford protection against the oxidation, which agrees with the results of electron microscopic observations which showed severe cracking of the oxide film. The studies by means of electron-probe microanalysis and X-ray diffraction indicated that tin was enriched in the alloy as the intermetallic compound $\mathrm{ZrSn}$ at the metal/oxide interface. The electron microscopic observations also indicated deposits of small particles on the metal/oxide interface, presumably corresponding to the precipitated $\mathrm{ZrSn}$. The oxide film on the breakaway specimen had a stratiform structure which appeared upon etching in 1\% HF-99\% $\mathrm{HNO}_{3}$. This implies that the oxide film consists of two types of oxide. layers having different tin contents. Since one layer consists of the particles observed at the metal/oxide interface, it is suggested that it corresponds to the oxidized layer of $\mathrm{ZrSn}$ deposits. The other type is considered to correspond to usual $\mathrm{ZrO}_{2}$. The fact that these two types of layers are alternatively piled up indicates that the oxidation of the $\mathrm{Sn}-\mathrm{Zr}$ alloy proceeds by the alternate oxidation of zirconium atoms and the $\mathrm{ZrSn}$ layer at the metal/oxide interface. Therefore, the oxidation mechanism of the $\mathrm{Sn}-\mathrm{Zr}$ alloy was deduced from the behavior of the $\mathrm{ZrSn}$ layer at the metal/oxide interface as follows.

When the $\mathrm{Sn}-\mathrm{Zr}$ alloy is oxidized, the zirconium atoms will be oxidized preferentially because zirconium has a larger thermodynamic affinity for oxygen than does tin, and the tin atoms therefore become more concentrated in the alloy near the metal/ oxide interface. When the tin content near the metal/oxide interface is increased beyond its solubility, tin will deposit as an intermetallic compound of tin and zirconium on the metal/oxide interface, consequently the oxide film will be separated from the alloy by the deposits of the intermetallic compound of $\mathrm{ZrSn}$ having the maximum tin content. When the alloy is covered by the $\mathrm{ZrSn}$ layer, the preferential oxidation of the zirconium atoms is stopped and the oxidation of the $\mathrm{ZrSn}$ layer will begin. After the oxidation of the $\mathrm{ZrSn}$ layer is completed, the oxidation of the alloy will begin again, and the 
oxidation will proceed by repetition of the sequence of steps including the preferential oxidation of zirconium atoms, the deposit of $\mathrm{ZrSn}$ at the metal/oxide interface, and the oxidation of $\mathrm{ZrSn}$ layer. The model of this stepwise oxidation is illustrated in Fig. 7.

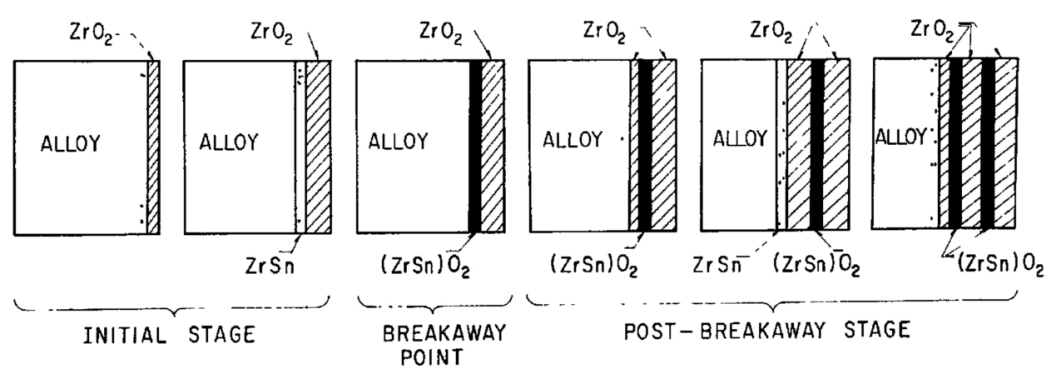

Fig. 7 Proposed oxidation process of $2.5 \% \mathrm{Sn}-\mathrm{Zr}$ alloy in oxygen.

It is very important to determine which step corresponds to the breakaway point. From the following considerations, it is reasonable to suppose that the breakaway will occur upon oxidation of the $\mathrm{ZrSn}$ layer. As seen in Photo. 3, since the $\mathrm{ZrSn}$ layer consists of the small particles which are poor in adherence to the oxide film, the oxide layer has a tendency to be peeled off from the $\mathrm{ZrSn}$ layer even by a small stress. Furthermore, the layer of oxidized $\mathrm{ZrSn}$ is considered to have physical and mechanical properties different from the neighboring oxide layer of normal $\mathrm{ZrO}_{2}$. This seems to induce a larger stress and a poorer adherence between the two layers. Therefore, it is suggested that when the $\mathrm{ZrSn}$ layer is oxidized, cracking between the oxidized $\mathrm{ZrSn}$ layer and neighboring oxide layer occurs, and the oxidation rate increases abruptly. On this basis, it is possible to understand the fact that the breakaway takes place suddenly after a certain period of oxidation which is a function of temperature and tin content.

From these considerations, the oxidation process of the $\mathrm{Sn}-\mathrm{Zr}$ alloy in oxygen can be expressed as follows :
(1) Initial stage of oxidation

$$
\mathrm{Zr}(\mathrm{Sn})+\mathrm{O}_{2} \rightarrow \mathrm{ZrO}_{2}+\mathrm{ZrSn}
$$

(2) Breakaway point

$$
\mathrm{ZrSn}+\mathrm{O}_{2} \rightarrow(\mathrm{ZrSn}) \mathrm{O}_{2}
$$

(3) Post-breakaway stage

$$
\begin{aligned}
& \mathrm{Zr}(\mathrm{Sn})+\mathrm{O}_{2} \rightarrow \mathrm{ZrO}_{2}+\mathrm{ZrSn} \\
& \mathrm{ZrSn}+\mathrm{O}_{2} \rightarrow(\mathrm{ZrSn}) \mathrm{O}_{2}
\end{aligned}
$$

where $\mathrm{Zr}(\mathrm{Sn})$ and $(\mathrm{ZrSn}) \mathrm{O}_{2}$ indicate the $\mathrm{Zr}-\mathrm{Sn}$ alloy and the misherystal or mixture of $\mathrm{ZrO}_{2}$ and $\mathrm{SnO}_{2}$, respectively. Since the tin oxide could not be detected in the X-ray diffraction pattern of the oxide film because of its lower content (2.5\%), the type of the tin oxide was not determined in the present work.

\section{Acknowledgements}

The authors wish to express their sincere thanks to Mr. Kazumu Sugimoto, Director of the Laboratory of the Mitsubishi Atomic Power Ind., Inc., for permission to publish the present work, to Dr. Shuichiro Takahashi, Assistant Manager of the Material Research and Development Department of the Laboratory, and to Dr. J. L. Daniel, Visiting Chief Research Scientist of the Laboratory, Research Associate of Battelle Northwest Laboratory, for their earnest support and discussion throughout this work. 